\title{
Volunteering Versus \\ Managerialism: Conflict \\ Over Organizational \\ Identity in Voluntary \\ Associations
}

(C) 2010 SAGE Publications

Reprints and permission: http://www. sagepub.com/journalsPermissions.nav

DOI: $10.1177 / 0899764010369386$ http://nvsq.sagepub.com

@SAGE

\section{Karin Kreutzer' and Urs Jäger'}

\begin{abstract}
This qualitative field study examines how volunteering and managerialism shape the organizational identity of six patient organizations from six different European countries. Volunteers represent a large part of the workforce in most voluntary associations. Even though the phenomenon of volunteering is becoming more and more important for organizations and society alike, so far it has only been studied at the individual level. The authors draw on the theoretical concept of dual organizational identities to describe the two differing collective self-descriptions that were present in the patient organizations. Drawing on 34 narrative interviews and focus groups, the authors document the differing perceptions of volunteers and paid staff about their organization's identity and show how the conflicting dimensions - volunteer identity and managerial identity-result in intraorganizational conflict.
\end{abstract}

\section{Keywords}

voluntary associations, organizational identity, volunteering, managerialism

'University of St. Gallen, St. Gallen, Switzerland

Corresponding Author:

Dr. Karin Kreutzer, Institute of Management, University of St. Gallen, Dufourstrasse 40a,

CH 9000 St. Gallen, Switzerland

Email: Karin.kreutzer@unisg.ch 


\section{Introduction}

The tensions that can exist between volunteers and employee co-workers remain one of the unpleasant secrets of nonprofit organizations.

Pearce, 1993, p. 142

Our volunteers do very valuable work and I appreciate that very much, but we have to become more professional.

President of a patient organization

Volunteering is widely regarded as a growing phenomenon (Anheier \& Salamon, 1999) and the employment of volunteers as one of the typical traits of voluntary associations (Harris, 1998). We intend to contribute to the existing literature on voluntary associations by responding to Tschirhart's (2006) "invitation": “There are numerous opportunities for scholars to significantly advance the study of associations" (Tschirhart, 2006, p. 536). Larger volunteer-involving organizations also employ paid staff, and the conflict between volunteers and paid employees not only has a long history (Paulwitz, 1988) but is also one of the major reasons for volunteers abandoning the organization (Rosenbladt, 2000). According to Hwang and Powell (2009), "the difference between 'amateurs' and 'professionals' is of particular importance as it raises issues that are at the heart of nonprofits' identity and culture" (Hwang \& Powell, 2009, p. 289). Tensions between volunteers and paid employees are caused by paid staff feeling threatened by volunteers, especially when the volunteers can perform the same functions as paid staff (Badelt, 2002; McCurley \& Lynch, 1997; Pearce, 1993; Regnet, 2002). Yet some authors claim that job threat is just one aspect in this very complex relationship requiring further empirical examination (Macduff, 1995; Pearce, 1993). Our findings suggest that this conflict is not only caused by job threat but by conflicting perceptions about the identity of the organization. In fact, due to the high level of ambiguity (Anheier, 2005; Beyes \& Jäger, 2005; Drucker, 1990; Pearce, 1993; Simsa, 2001), nonprofit organizations are often characterized by conflicting multiple organizational identities (Glynn, 2000; Golden-Biddle \& Rao, 1997; Jäger \& Beyes, 2010; Young, 2001). Furthermore, identities of individuals in key organizational roles (e.g., administrators and board members) shape and construct the hybrid identities of the organization, which then cause intraorganizational tensions and conflict (Glynn, 2000). As volunteers and paid staff are present at each level of voluntary associations (the board of directors consists of volunteers; executives are paid), we can safely expect that both groups shape the organizational identities considerably.

To date, volunteering has mainly been empirically analyzed at an individual level, addressing the questions of who volunteers (demographics; Gaskin \& Smith, 1997); why individuals volunteer (motives; Clary, Snyder, \& Stukas, 1996; Omoto \& Snyder, 1995); how volunteers interact, respond to, and cope with the organization (organizational behavior; Pearce, 1993); or how to lead volunteers (Jäger, Kreutzer, \& Beyes, 
2009). An exception is the study by Kelley, Lune, and Murphy (2005), who analyzed the importance of the phenomenon volunteering for organizational transition. The authors demonstrated the effects of organizational transition (professionalization) on the experience of volunteers and the breakdown of volunteer commitment in an organization called prevention point. Therefore, we assume that the phenomenon volunteering is part of a collective self-description and can be analyzed as a dimension of organizational identity. Furthermore, studies that empirically assess the phenomenon at an organizational level (Kelley et al., 2005; Wood, 1996) often lack a strong theoretical background and do not sufficiently provide the (practical) implications of their findings.

Thus, volunteering can be seen as an organizational phenomenon (Kelley et al., 2005), which our interview partners described as "the way we do things around here." Howlett and Rochester (2007) suggested that this "volunteer way of doing things" might be characterized by basic democratic structures and nonmanagerial logics in which integration is more important than efficiency.

In this article, we intend to show how this emphasis on nonmanagerial logics, which is part of the volunteer dimension of organizational identity, conflicts with the growing professionalization efforts many nonprofit organizations are making. These efforts include the introduction of business-like instruments from the for-profit world (Dart, 2004) and a higher involvement of paid professionals (Hwang \& Powell, 2009; Salamon, 1993; Weisbrod, 1998), which again enforces the conflict between volunteers and paid staff. In fact, Harris (1998) states that the implications of two organizational features of associations merit particular scholarly attention: being run by volunteers and being pulled toward bureaucratic structures.

Conflicting beliefs among members about their organization's identity can have significant negative impact. Jehn, Northcraft, and Neale (1999), who examined members' perceived disagreement about what their group's real mission or goal should be, found that "it is the diversity associated with values . . . that causes the biggest problems . . . in work group performance and morale" (Jehn et al., 1999, p. 758). Disagreement about organizational identity "is a struggle . . . over the very soul of the institution" (Albert \& Whetten, 1985, p. 272). Therefore, we intend to make nonprofit leaders aware of how the conflict between volunteers and paid staff might arise as a result of different perceptions of the organization's identity and that this issue requires specific attention. We identify important implications for the leadership and management of dual-identity associations.

To summarize, volunteering has thus far been mainly studied at an individual level, and organizational identity (Albert \& Whetten, 1985) seems to be a promising theoretical construct for understanding the peculiarities of the phenomenon at an organizational level. In this article, we will describe two identity dimensions held by different groups within the associations studied: volunteer identity and managerial identity. We will then analyze how conflict between the two groups arises as a result of conflicting beliefs about the organization's identity.

The present article is structured as follows: We begin with a review of the relevant literature on volunteering, managerialism, and organizational identity. Next, we explain the methods of data collection and analysis and the reasoning behind choosing 
them. We then apply the concept organizational identity to patient organizations in Europe, describing the two dimensions of their identities: volunteer and managerial. We will present the areas of conflict that result from the different perceptions of the organization's identity. Finally, possible shortcomings of this approach and opportunities for future research will be addressed.

\section{Literature Review}

\section{Volunteering}

Volunteering can be defined as time that is given freely and without pay to any organization that has the aim of benefiting people in a particular cause (Gaskin \& Smith, 1997). Furthermore, the majority of volunteers have no contractual obligation to the association (Pearce, 1993). The most obvious formal characteristic of volunteers is the absence of pay. Thus, volunteers have no monetary (or legal) reason for joining or staying with the organization. This creates unique type of pressure for an organization that depends on volunteer work because of the association's awareness that its members could abandon the organization at any time (Pearce, 1982).

The unit of analysis in the literature on demographics, motives, and organizational behavior of volunteers is the single volunteer (individual level). A notable exception is Pearce (1993), who examines (among other aspects) the structural design of organizations involving volunteers and finds that it is different from the structural design of organizations that are run exclusively by paid staff. Furthermore, the practitioneroriented literature on volunteer management described in the next section offers more insights into the organizational perspective on volunteering.

\section{Conflict Between Volunteers and Paid Staff}

Concerning the conflict between volunteers and paid employees, management literature offers little advice despite the apparent severity of the problem. An exception is the chapter in the Volunteer Management Handbook by Macduff (1995), which addresses the relation between volunteers and paid staff. She defines characteristics of an effective volunteer-staff partnership from her experience as a consultant in the field of volunteer management. She emphasizes the importance of communication, training, clear objectives, and trust. However, she fails to identify the reasons for this bad relationship, and she does not take the organizational perspective into account.

Practitioners continue to report ongoing conflicts between paid and nonpaid staff in their organizations (Regnet, 2002). Although the conflict as such has existed for a long time and has a significant negative impact on organizational members, surprisingly few studies examine the conventional wisdom empirically (Brudney \& Gazley, 2002). It seems to be a crucial challenge for managers in practice to deal with these tensions. However, before handing out golden rules too quickly, one has to understand what this conflict is really about. From our data, we learned that staff members did not only 
perceive volunteering as part of their individual identity but also as part of their organization's identity ("What do we think this organization is really about?"). Volunteering seems to be more than just an individual's choice of on how to spend his or her spare time; it is also seen as "the way we do things around here." Consequently, we applied the construct organizational identity to describe and understand the collective selfdescription of volunteers (and paid staff) about their organization. Paid staff members had different understandings of the organization's identity, which correspond to the concept of managerialism.

\section{Managerialism}

Managerialism is generally understood "as the dominance of management practices and ideas" (Maier \& Meyer, 2009, p. 8) and has been conceptualized as "a specific form of organizational structure that incorporates effectiveness, efficiency, agency, and progress as central norms" (Maier \& Meyer, 2009, pp. 32-33). More provocative, it has been defined as "a set of beliefs and practices, at the core of which burns the seldom-tested assumption that better management will prove an effective solvent for a wide range of economic and social ills" (Pollitt, 1993, p. 1). Many nonprofit organizations have introduced management instruments and continue to do so. The reasons are manifold. One reason seems to be governmental obligations: A study by the Volunteer Centre U.K. revealed that about one in eight organizations that had entered into contracts with the government said that as a consequence they had introduced more formal procedures with volunteers (Hedley \& Smith, 1994).

However, the widespread belief that the application of management instruments can optimize the performance of any organization in any situation has not gone unchallenged (Alexander \& Weiner, 1998; Brainard \& Siplon, 2004; Kelley et al., 2005). Although lacking empirical evidence, Smith (1996) suggests that the new management culture imported from the paid workplace could be inappropriate and at odds with the culture and values of volunteering. He further states that the heavy emphasis on formal management processes might deter volunteers belonging to marginalized groups from coming forward. The work of Mancur Olsen suggests that when, as a consequence of market signaling changes, community organizations become more professionalized and structured to a greater degree around principles of rationality, the formal definition of rules, and construction of bureaucratic roles, then organizations become more exclusive and hence less participatory and less democratic (Olson, 1965).

We apply the theoretical concept of organizational identity to describe and analyze the volunteer and managerial perception, which were present in the organizations studied.

\section{Organizational Identity}

Organizational identity is a key intangible aspect of any institution. In 1985, Albert and Whetten first raised the issue of whether we can metaphorically project the idea of an identity on organizations to describe and explain their dynamics. Organizational identity comes into play when organizations face hard decisions, when the discussion of 
goals and values becomes heated, when there is deep disagreement or confusion and when questions such as "Who are we?" or "What do we want to be?" arise. According to Albert and Whetten (1985), organizational identity reflects the organization's attributes, including its core values, organizational culture, modes of performance, and products. They defined organizational identity as those characteristics of an organization that its members believe are central, distinctive, and enduring (Albert \& Whetten, 1985). In other words, organizational identity consists of those attributes that members feel are fundamental (central) and uniquely descriptive (distinctive) and that persist in the organization over time (enduring). However, more recent authors questioned whether organizational identity is truly enduring and resistant to change. In this article, we follow this literature stream, which adopts a social constructivist perspective on organizational identity. These authors assert that organizational identity resides in collectively shared beliefs and understanding about central and (only) relatively permanent features of the organization (Corley \& Gioia, 2004; Dutton \& Dukerich, 1991; Gioia, Schultz, \& Corley, 2000; Gioia \& Thomas, 1996). According to these authors, shared understandings are the results of the sense-making processes (and not of sense giving) carried out by organizational members. Thus, these shared understandings are periodically renegotiated among members and are not enduring. Similarly, Weick (1995) claims that organizational identity is a collectively held frame within which organizational participants make sense of their world.

Organizations often struggle with dual identities, which can be developed when members incorporate two or more different and potentially conflicting dimensions that are not normally expected to go together (Albert \& Whetten, 1985). These dimensions can be separately maintained by different segments of the organization and generate an ideographic identity, or are diffused throughout the organization, and produce a holographic identity. The duality of identity in voluntary associations examined in the present study is ideographic in nature; contradictory identity dimensions - volunteering and managerialism - coexist and are claimed by different groups (volunteers and paid staff) within the organization.

The concept of dual organizational identities is especially compelling for nonprofit organizations because such organizations often operate in ambiguous environments (Young, 2001). Many nonprofit organizations have identities composed of contradictory elements because they contain actors within the organization who come from different professions (Glynn, 2000; Golden-Biddle \& Rao, 1997) and because they must be responsive to multiple stakeholder groups with divergent viewpoints (Scott \& Lane, 2000). Of all of the sectors involved, the nonprofit sector is the most ripe for corporate ambivalence. Ambiguity seems to be characteristic of nonprofit organizations, no matter whether we follow Drucker (1990), who states that nonprofit organizations have no bottom lines at all, or whether we believe Anheier's (2005) claim that nonprofit organizations do indeed have bottom lines but that they are multiple (in contrast to profit enterprises where the bottom line is profit). Anheier suggests that nonprofit organizations have several bottom lines because "no price mechanisms are in place to aggregate the interests of clients, volunteers, staff, and other stakeholders, and to match costs to profits, supply to demand, and goals to actual achievements" 
(Anheier, 2005, p. 227). As a result, several rationales operate in third-sector organizations. Beyes and Jäger (2005) propose the term multidiscursive organizations to describe how nonprofit organizations, different from for-profit companies or publicadministrative agencies, lack a unique, consistent reference system. Simsa (2001) sees this multilingualism as one of the typical traits of nonprofit organizations, which have to balance different nonprioritizable logics of differentiated functional systems. Furthermore, for voluntary associations, much more than for large bureaucratic servicedelivery nonprofits, organization is a matter of balancing competing interests, goals, and values (Harris, 1998).

\section{Method and Sample}

We chose the methodology mainly due to the explorative nature of the research question and the scarce existing research on voluntary associations. We thought that the nature of the research problem required a more detailed view of the topic. Consequently, we set out to study the organizations in their daily working routine, trying to obtain a close-up view of their management problems. We tried to gain an insider perspective by spending time in the field, collecting extensive data, and by personally engaging in the complex process of qualitative data analysis by sorting through large amounts of textual data.

As noted above, in this article, we follow the social constructivist perspective on organizational identity. Consequently, an interpretive methodology was adopted. Furthermore, a qualitative research design is appropriate because it is effective in investigating sensitive matters such as conflict (Kumar, Stern, \& Anderson, 1993; Mouly \& Sankaran, 1997).

\section{Sample}

As the aim of this research project was to empirically investigate the phenomenon of volunteering at an organizational level, our unit of analysis is organizations involving volunteers and not the individual volunteer.

We examined six patient organizations from six different European countries. In patient organizations volunteers play a crucial role. They are the members and drivers of the self-help groups that form the heart of the association. Patient organizations represent a typical example of voluntary associations. Voluntary associations can be defined as private, membership-based organizations in which membership is noncompulsory (Anheier, 2005), and they represent a substantial part of the third sector (Smith, 1997). Voluntary associations differ from other nonprofit organizations in important ways, for example, being volunteer driven or the importance of members. The patient organizations we analyzed were born as umbrella associations of several grassroots self-help groups for patients affected by one specific disease. Nowadays patient organizations play an important role in informing patients, caregivers, health care professionals, and the general public about the disease. Most patient organizations provide highly specialized products and services for their clients and successfully lobby on behalf of patients 
at government level. The associations examined in our study had between 3 and 206 paid employees; the estimated number of volunteers was between 40 and 4,500. The employee-volunteer ratio was quite similar across the associations. All of the organizations studied relied heavily on the work of volunteers at all levels of the organization (from the self-help group member to the president of the board). The six associations were from Denmark, Ireland, Norway, Sweden, Switzerland, and the United Kingdom.

Studying one patient organization in depth, we found that it was in the process of developing from providing services mainly to members to delivering services to the general public (Kreutzer, 2009). This transition process is appropriate for studying organizational identity as questions arise at times of severe organizational stress (Albert \& Whetten, 1985; Young, 2001). As the patient organizations under study experienced considerable growth during the time of transition, they represent an adequate source of data for studying the identity attributes present in the organization. Furthermore, these organizations were appropriate for studying dual organizational identities because two of the four conditions Albert and Whetten (1985) named for postulating a drift toward dualism in the life cycle of an organization are met: environmental complexity and the problem of identity divesture. First, the environment in which these organizations were embedded grew more complex over time and, second, during the period of growth versus the general public these organizations acquired new identities.

\section{Data Collection}

The data collection consisted of two phases. First, we conducted an in-depth case study analyzing one association from Switzerland. We interviewed 17 of the organization's internal and external stakeholders: the president and the managing director as well as employees, volunteers, members, partners, and a government officer. In the second phase of data collection, interviews with representatives from five different national patient organizations were conducted. In each of these associations, we interviewed the volunteer president of the board, the paid managing director, and other stakeholders until theoretical saturation was achieved. Thus, we were able to compare our results from the Swiss context with organizations working in different European countries and enhance the transferability (Lincoln \& Guba, 1985) of our findings.

In total, 34 narrative interviews were conducted between June 2006 and August 2008. The narrative approach was selected for a number of reasons. First, as Weick (1995) noted, stories give meaning to the events, actions, and objects in our lives. We not only make sense of our world in narrative terms but we also proactively plan and enact narratives that are consistent with our expectations and values (Czarniawska, 1997). For this reason, narratives can be a valuable source of insight about organizations. Second, as Czarniawska asserts, not only is narrative "the main source of knowledge in the practice of organizing," but also, just like individuals, "organizations need a coherent narrative," and identity may be appropriately conceptualized as a "continuous process of narration where both the narrator and the audience are involved in formulating, editing, applauding, and refusing various elements of the ever-produced 
narrative" (Czarniawska, 1997, pp. 5-6, 24, 49). Thus, narratives have been identified as an important source for studying organizational identity (e.g., Humphreys \& Brown, 2002). Third, one great strength of narrative interviews is that they represent the strongest attempt to go beyond the question-response-type interview trying to avoid restructuring through the researcher in the interview (Schütze, 1977).

Because we were interested in our interviewees' experiences, we used open, personal questions and we were looking for experiences, examples (Froschauer \& Lueger, 2003; Hermanns, 1991; Mason, 2002), critical incidents (Flanagan, 1954), and narrations about the organization's history (Kieser, 1994). Hence, we did not ask our informants directly about the identity of their organization. In this way, we could elicit vivid narrations about everyday life in the organization. The interviews had a medium duration of approximately one hour. Following each interview, minutes were written.

We collected further data with different methods - in the sense of triangulation - to systematically extend and complete the possibilities of knowledge production. The triangulation allowed us to increase scope, depth, and consistency in the methodological proceeding. A second source of data was internal documents such as minutes of board meetings and strategy sessions that took place from 1990 to 2006 . We also observed several board meetings in the Swiss association. Furthermore, we organized two focus-group discussions (Morgan, 1988) with our interview partners to discuss the results of the interview analysis. Thus, concerning the criterion of credibility (Lincoln \& Guba, 1985), the focus groups showed that our findings are believable from the perspective of the participants.

\section{Data Analysis}

The transcribed interviews and focus-group discussions as well as the minutes written after the interviews formed the basis of our analysis. A coding software was used to screen and sort the textual material before interpreting the data according to the fine structure analysis and the system structure analysis by Froschauer and Lueger (2003). The software served to identify the text units that needed to be interpreted in detail (Froschauer \& Lueger, 2003). The field data were coded based on the open coding method (Strauss \& Corbin, 1998) to identify the organizational characteristics its members believed to be central, distinctive, and enduring, so-called first-order themes (Geertz, 1983). Here, for example, we found a prevalence of narrations by volunteers about the scarcity of resources or about the ongoing conflict with paid staff. The fine structure and system structure analysis, which focuses on the interpretation of single text units, served to generate second-order themes (Geertz, 1983) such as the dimensions of each identity. We conducted our interpretation process close to the transcribed texts (Van de Ven \& Poole, 1990, p. 321) and tried to discipline ourselves not to judge on the basis of our own theoretical assumptions. In this way, we discovered that the differing beliefs and perceptions about the organizational identity (second-order themes) caused the conflict. We compared different sources of data (interviews, internal documents and the transcripts of the focus group discussions) to disclose any systematic bias present and 
thus increased the dependability (Lincoln \& Guba, 1985) of our findings. The data were analyzed by a team of two researchers with heterogeneous backgrounds. Thus, we were able to enhance the confirmability of our findings by having one researcher take the role of a "devil's advocate" (Lincoln \& Guba). Furthermore, we actively searched for negative instances that contradicted our prior observations.

\section{Findings}

When observing strategy sessions of the Swiss patient organization, the focus groups, or conducting a workshop with representatives from patient organizations from all over Europe, one question emerged again and again: Who are we? Most organizations were founded in the 1980s and had experienced considerable growth since then. Most of the organizations' members felt that the strategic focus, the organizational culture, and its core values had also changed. However, even though it was clear to all of our interview partners that something had changed, opinions differed about what the organizations should be all about now.

In general, volunteers pointed out different beliefs about their organizations from those of the paid staff. We refer to these two identity dimensions as volunteer identity and managerial identity. As a matter of fact, volunteers from different organizations had perceptions that were more similar to each other than those of the volunteers and paid staff of the same organization; the same was true for paid staff. This finding resembles the results from Pearce (1993), who found the same to be the case for the organizational behavior of volunteers and paid staff. Thus, in these associations two apparently contradictory identity dimensions coexisted and were claimed by different groups within the organization (volunteers and paid staff). It is interesting to note that we did not find significant differences among volunteers' perceptions about their organization's identity at the different levels of the associations; that is, the narrations by the people working in the central office differed according to their being volunteer or paid, but the narrations used by volunteer leaders of local self-help groups and volunteers in the central office barely differed.

There were some exceptions to this finding, which we refer to as quasi volunteer and quasi managerial. One former managing director of the Swiss association is an example of a quasi-volunteer employee as her perceptions about the organization and her work behavior were more volunteer like, even though she was paid. An example of a quasi-paid volunteer is a former president of a patient organization from another country. He came from the business world and ran the organization as he had run his company.

\section{Volunteer Identity}

The volunteers strongly believed that their associations were voluntary organizations. The idea of helping each other on a voluntary basis was behind the foundation of the first self-help groups, which later formed the association. Patients affected by a specific 
disease and their family members gathered with others to share their experiences, to give and receive advice, and to start projects with the aim to make life easier for people with the condition and their caregivers.

In the following, we will describe different dimensions we extracted from the selected narrations about the volunteer identity within the organizations studied.

"We are a volunteer organization." Volunteers strongly felt that the organization belonged to them and that they carried a huge part of the workload. An often recurring dimension of their collective self-description was how they as volunteers sacrificed themselves for the cause and the organization: "The volunteers put in longer hours, those that are active. Well, at the moment we more or less devote our lives to this." Furthermore, they put emphasis on the fact that the long hours they worked for the organization were their "free time": "I have a full-time job. I do this for free. I am a chemist, actually. This means, well, I simply don't sleep enough.” As volunteers work without pay, they represent an invaluable resource for any organization. All members (paid or volunteer) reported how important it was to thank the volunteers and to acknowledge their achievements on a regular basis. It seems to be part of the volunteer organizational culture to continuously ensure volunteers of their importance for the organization. A volunteer explained her experience as follows:

I need to get approval for ideas. I need to have some support to manage to do it. I need to have feedback; I need to know that they think what I am doing has importance for the members. I need to hear it from them. If I hear it from others outside the organization, it's nice, but the important thing is that I hear it from those I am working for.

Similarly, a volunteer member of another association stated, "It is praise what we need here, more than anything else. Praise and respect. We have to say 'bravo,' 'thank you,' and 'please do it again tomorrow.' That is very important, in my eyes."

Finally, it seems to be essential for our volunteer interview partners that all work that can be done by volunteers is actually done by volunteers: "It is a principle of our organization that most things are done on a voluntary basis, all of the work of the selfhelp groups, for example." This seems to be a concept difficult to put into practice as the border between work that can be done by volunteers and work that cannot be done by volunteers is far from clear and might vary from person to person.

The important role volunteers play in such a voluntary organization also becomes obvious in another aspect. As mentioned above, volunteers do not have a contractual obligation to their organization; as a consequence, it is crucial to ensure that volunteers are happy with what they are doing:

If you are volunteering and you disagree with how things are done, you are just going to quit and leave. So you have to have an organization where you take care of the volunteers and you listen to what they say and take it seriously. 
Similarly, a volunteer board member reported how volunteers need to be treated in her eyes: "I attached a lot of importance to making sure we were all living together in harmony. And how you treat people, that is a real credo of ours: You should take everybody seriously and you shouldn't send away anybody." It becomes obvious that in contrast to paid staff there was no selection process for volunteer workers. In fact, the volunteers explicitly aimed to include and integrate everybody who was interested. There were few or no formal requirements volunteers had to meet to be able to work for the organization: "We might have the skills between us, my colleague and I, but we don't have it on paper."

"We are a poor organization." Our volunteer interview partners pointed out that they were working without pay because the organization was too poor to pay them. It seems to be obvious that a social organization's funds are always scarce and thus the decision to invest them has to be made very carefully. "Financially, we are always at the limit," a volunteer said, "We always have a bad conscience when we invest the money in one project because this means that we cannot finance another one." Thus, a potential waste of resources becomes a major threat to the organization. The missions of the organizations studied were framed in very open language (e.g., "to support all people with [the disease] and their families, friends, and caregivers"), and it was inevitable that there would never be enough money to actually achieve this mission.

The initial decision to employ the first paid staff member had provoked a lot of discussion and was a decisive milestone in the history of each of the associations we studied. Volunteers were asking themselves why should we spend so much money on a paid person if volunteers do the job so well? For many volunteers, it made no sense to pay a salary to someone who performs the same or similar tasks volunteers do for free.

"Having too much money is always a danger," a former chairman of one of the associations reported, "You should always have just as much money that you don't get the idea of inventing luxury activities or something which would bother your volunteers." If volunteers perceive that the resources of the organization are wasted, they might decide to reduce their (unpaid) work for the organization. It seems to be a defining element of the volunteer organizational identity that there is never enough money, so every helping hand is needed. In fact, our volunteers needed the feeling to be needed. This will be discussed in the next paragraph.

"Volunteers run our organization." We asked all of the volunteers about their personal story within the organization, how they had initially gotten in touch with it, and how they had become involved in the work and ended up in the position they held. The answers we received were unanimous: "They asked me." Some had been members of the association for some time when another volunteer came to them to ask for their active involvement. Others were not involved with the organization at all before friends or family members asked them for their active support. One interview partner even spoke of a "discovery": "I suppose, they discovered that I was able to do those things." 
As indicated above, it seems to be crucial that volunteers feel they make a difference. We heard many times from our interview partners, "They need me." However, this is sometimes perceived as a burden: "U. says, they are dependent on me. There is nobody else who could do these things."

In addition to the feeling of "they need me," volunteers pointed out that it was important for them to have sufficient leeway to develop and implement their ideas. To have enough elbow room was a motivating experience for our interview partners: "I could do a lot on my own initiative." Another volunteer said, "Sometimes it was very convenient, ... we could go to meetings and agree things, with pharmaceuticals, for example. We made quick decisions and if you have too many officers, you have to go back and discuss and everything." She spoke not only about the freedom to decide but also about the absence of hierarchical levels. There was no officer she had to coordinate her decisions with. This lack of a formalized division of responsibilities, which was accompanied by greater opportunity for each individual to shape and influence the organization's activity, was a very motivating aspect for her and many other volunteers we interviewed. Nonstructured working processes, no clear job descriptions, and informal procedures were elements of the daily routine many volunteers described. "My job description is 'everything'. You name it, I do it," the chairperson of a Northern European association declared. No volunteer wanted to do only the unattractive support duties; so to maintain volunteer participation, these duties were shared. The quasivolunteer former managing director explained, "I did everything. We all did everything, everybody. I answered the phone, gave advice, organized events, and I also did fundraising and accounting." When talking about her work for the association, it became obvious how she (like many other volunteers we interviewed) enjoyed the "creative chaos" and the feeling that there was a lot to be done.

"Our association relies on flexibility and personal networks." Volunteers do their (volunteer) work in their spare time. It is obvious that the free time they can dedicate to the organization is restricted by other responsibilities they have, for example, toward their families or their regular work. A paid staff member put it this way: "If you work as a volunteer, it is your spare time and you do the work when you have time. Some of the volunteers have their own work, which is even more difficult then." These time restrictions that volunteers are subjected to lead to unclear working hours. None of the volunteers we interviewed worked from nine to five. Some worked more than 12 hours a day; others worked on weekends or in the evening. Many volunteers did a large part of their work outside the association's office, mainly at home. On one hand, this led to a high flexibility among the volunteer workers as they were willing and able to work long hours in times of a heavy workload and to disappear for weeks if there was less work. On the other hand, paid staff criticized the volunteers as being unreliable: "You might think they are going to do something with you. And then they don't."

The volunteers reported not having clear boundaries separating their private life from their life as a volunteer. They used all the contacts they had to advance the 
mission of the organization. After all, the volunteers themselves had once been asked to help by someone they knew. A board member explained to us how she creates a network: "I create opportunities. I talk to different people, to our members, to people I know. And then I try to find someone who knows someone who can help us." Thus, instead of giving the order (or task) to any supplier, she finds somebody who knows somebody she can convince to do it for free or with a reduced salary. This alone might not be so peculiar, but in some associations the logic was even turned around: Volunteers ordered services and products from friends the association did not really need, just because they were for free.

Due to the scarcity of resources some volunteers had developed an extraordinary ability to improvise. A volunteer told us a story about how she had organized a huge information meeting for patients:

You have to find a room that is nice and big enough and then you have to talk to the municipality, or whoever the room belongs to, and you have to convince them to give you the room for free. You need good speakers, neurologists, and if you don't find them in the area, you have to bring them in from far away. Then you need music and food. Maybe someone knows someone who plays in an orchestra or a band. We cannot afford a caterer or pay for music. Food can be prepared by the members, the ladies loved that. It was a great event and we won many new members.

A few paid staff members expressed concern that the excessive use of these informal networks might put volunteers into situations of a conflict of interest in which their private interests collide with the interests of the association.

"We are the ones affected." If they were not affected by the disease themselves, most of the active volunteers had a connection to the disease; they had a friend or a family member with the condition. Thus, all volunteers knew the cause they were fighting for very well from their personal experience. A lady said to us, "Don't tell me anything about the disease; I've been living with it for almost 25 years now. I know what I am talking about." Due to this emotional proximity to the cause, the volunteers had very good knowledge of the needs of the association's target group.

As members, the volunteers owned the association. Thus, the volunteers felt that they were employing paid staff to help them to fight the disease. They expected staff members to act as their assistants and facilitators. Thus, volunteers felt it was the job of the employees to help them implement their ideas: "His task is actually to make happen what the general assembly has decided. So it will be him to carry that out." In the end, they were the ones affected by the disease and fighting against it, and paid employees rarely had a similar personal history. As a consequence, some of the paid staff members we interviewed seemed to be compelled to prove that they were indeed connected to the disease:

I have no one in my family with the disease, but now I know thousands of people with the condition, and some of them are good friends of mine. So I do personally know many people with the disease, just not in my family. 
As they were affected themselves, it was very important for the volunteers to react appropriately to the needs of other patients:

You are getting ideas of the people all the time coming in and then you try to respond. For example, if someone says, look, there is no information about pregnancy with Parkinson's. Then maybe another organization would say we will plan to produce it next year. And we say, all right and we start to do it.

A staff member found that the volunteers exaggerated in their willingness to help:

Someone calls and says you should do this and this. Then some kind of, not panic, but hustle comes up, that is surprising. I mean, if there is one person expressing a need, you don't have to stop every other activity and run to help him.

Furthermore, he pointed out how his association could help many patients more effectively if, instead of responding to every single need the members expressed, the resource allocation were planned more thoroughly. By contrast, volunteers felt very strongly about the principle that they not send away anyone who needed help but rather do anything to support that person.

Being actively engaged as a volunteer can have significant positive impacts on the people affected by the disease. A specialized neurologist explained that

it is motivating; if he has a meeting with someone from the ministry, he has to go there and then he will pull himself together and go. Otherwise, he might remain at home and say, oh, the weather is bad today and I don't go out. In that sense, it has a therapeutic effect.

Furthermore, volunteering for the associations represents a way to integrate patients into society who would otherwise remain isolated and lonely: "The leader of our self-help group, she's 86 years old and in great health-a wonderful person. She does the welcome speech; we do everything else."

\section{Managerial Identity}

When we interviewed paid staff, we realized that they expressed in their narrations different beliefs and perceptions about the organizations' identity than the volunteers in their narrations. In the previous section, we outlined in detail what the volunteers' perceptions of the organization's identity were. Even though some of the contrasts between volunteers' and paid staff's narrations were made clear in the preceding section, the most salient aspects of managerial identity will be depicted more in detail in the following. It is interesting to note that not only the content of the volunteer and paid staff narrations about the organization was different but also the lexicon used. 
"There is no work like professional work." When talking about professionals, it is important to clarify what we mean by the term. We will use the term professionals to refer to persons qualified with a specific professional qualification (e.g., doctors, accountants). Thus, this section is not about working professionally (in terms of well organized or effective).

All of the paid employees we interviewed had a specific qualification in the job they were performing, for example, in social work, accounting, or communication, and used the specific lexicon of their profession. They were convinced that an organization based only on volunteer work cannot work: "If you only have volunteers, you will never have the people who can, well, frame the organization."

As noted above, almost none of paid staff members we interviewed were affected by the disease (nor were any of their friends or family members). Especially, the associations employing a large number of people had few or no volunteers working in the central office (anymore). A manager explained this distance to the patients and caregivers: "The members down at the bottom are far away from my office, far away from everyone in our system." The missing emotional proximity to the cause the association was actually fighting for had some curious consequences:

I think, it is sometimes the tone, the way we talk about things, when you work with the disease every day; you can get a little rough in your tone. It's not because you have anything against them, no, no. It is just, you get a little rough. So it's better if they're not around.

In the eyes of the employees, the association serves as a guardian of the patients by supporting them and fighting for their rights. In some large associations, paid staff had even reduced the role of volunteers in the association only to user involvement: "We have people we consult with. They sit in our meetings, so we find out what they think, and they advise us on our publications." An employee of a large association reported, "When we talk to politicians, we bring someone with the disease." Staff members noted that there were clear limits even to user involvement. A managing director said, "But my opinion is that you have to choose the skills before the disease. It is more important to have the right skills than to have the disease." Similarly, a communication officer stated, "You need know-how; it's not enough to be affected by the disease." Originated to reduce the distance between the central office and patients and caregivers (their target group), the strategy of user involvement limited the role of patients in the association to consultants at the most.

"Money, money, money." During our interviews, we observed that a substantial part of the volunteers' narrations was about the disease and what it means to be affected by it. For some of them, it was very difficult to abstract from the disease to the organization and its problems. By contrast, the main narration of paid staff members was often about money and how they had been able to obtain funds. In these narrations, paid staff also used managerial lexicon, such as "return on investment," "break even," or "customer relationship marketing." 
On the question of what the three major challenges would be that her association will face in 5 years, a managing director responded, "money, money, money." Another manager pointed out how decisive the provision of funds had been for the organization: "Without money, you cannot do anything. We have been able to get more funding and raise our budgets year by year. That was the most important thing we have done." Similarly, the executive of a northern European organization said, "Now that we have money, everything has changed, everything."

However, employees emphasized the importance of investing money to be able to raise more funds for the organization. Paid staff regarded mailing campaigns as a central feature of the organization. These campaigns require a fairly high initial investment and bear a certain risk. A traumatizing experience for the volunteers of an association was the 2004 tsunami: They had started a fundraising campaign with a high investment and almost everything was lost because their campaign had just begun when the attention to the disease and the willingness to donate were drawn away by the disaster. As a consequence, a volunteer board member of that association resigned because he was not willing to take a similar risk again: "In the first place, I joined [the association] because I wanted to help others, ... not for gambling."

Professional fundraising campaigns were a controversially debated issue in all associations. Many volunteers feared for the reputation of their association and therefore did not approve of "begging letters." A quotation from a managing director shows how different her managerial approach was: "I worked in marketing for a publishing company before. Today I sell [the disease] and you can sell [the disease] way more easily than anything I sold before. It's fantastic; you can sell [the disease] very, very well.”

"Our organization relies on standardized procedures." The paid employees had different professional backgrounds and were hired for specific positions. As they had distinct expertise in one specific field, responsibilities were distributed accordingly. Some volunteers had difficulty accepting this specialization and clear separation of duties in the association. One volunteer reported how the employees tried to make her delegate some of her tasks: "They had to tell me, look, you don't have to worry about paper clips."

By contrast, all of the paid staff members clearly favored a high degree of formalization in the daily office routine. A managing director explained why it was important in his eyes to create positions that could be filled in by different persons:

Processes should be well structured; otherwise, everything relies on one person and that can be catastrophic. We have to make sure that this organization is run well enough so you can change people in important positions and nothing is going to break down.

Formalization, structuring of work processes, division of labor, and further specialization were the tasks the employees believed to be crucial for the success of the association. Some volunteers criticized these efforts as a waste of money: "The patients should benefit directly from the money that comes in; it shouldn't be wasted in bureaucracy." 
Table I. Identity Dimensions

Identity dimension

\begin{tabular}{lll}
\cline { 2 - 3 } Processes & Managerial identity & \multicolumn{1}{c}{ Volunteer identity } \\
\hline Resources-upstream & Fundraising & Scarcity of resources \\
& Predictability & Relationship-driven Conduct \\
& Investment & Free-of-charge procurement \\
Services_downstream & Structure & Creativity \\
& Distance & Emotional proximity to the cause \\
& & Readiness to help others \\
\hline
\end{tabular}

Furthermore, employees complained about the obstacles basic democratic decision making poses for effective management. "The needs of a volunteer are different from the needs of a professional. And the time frames are different," a managing director said. He reported how endless discussions in the board were slowing down and delaying important projects: "The work of the board is quite informal and unstructured. It is difficult for us. They meet only every 3 months. Sometimes you need quick decisions and then you have to wait for the next board meeting."

\section{Conflicting Perceptions of Organizational Identity}

It is important to emphasize that all organizational members fully shared the mission of their association. However, the perceptions and beliefs about how these goals should be reached varied. In general, we were able to identify two differing dimensions of organizational identity that were present at the same time. As noted above, these two identity dimensions did not simply represent the views of two organizational groups. We also found quasivolunteer staff members and quasimanagerial volunteers; however, they were the exception.

Table 1 depicts the two identities and highlights the different perceptions of how the organization should reach its mission. Generally, in voluntary associations two main processes can be differentiated (Moore, 2000): provision of resources (upstream) and service delivery (downstream). Unlike in for-profit firms, in nonprofit organizations these two processes often function largely independently of each other (Brown \& Moore, 2001).

As we have shown, volunteer identity is composed of perceptions of scarcity of resources, relationship-driven conduct in fundraising, and free-of-charge procurement of resources. The main focus of the volunteer identity lies in the services, where elements such as creativity, emotional proximity to the target group, and a readiness to help others were emphasized. By contrast, managerial identity is characterized by ideas of professional fundraising, predictability and investment concerning resources, and by structure and distance concerning the organization's services. 
Table 2. Conflicting Identity Dimensions

\begin{tabular}{lll}
\hline & \multicolumn{2}{c}{ Conflicting identity dimensions } \\
\cline { 2 - 3 } Conflict areas & \multicolumn{1}{c}{ Volunteer identity } & Managerial identity \\
\hline $\begin{array}{l}\text { Authority: Each identity claims } \\
\text { authority to lead the } \\
\text { organization }\end{array}$ & $\begin{array}{c}\text { "We are a volunteer } \\
\text { organization" } \\
\text { "Volunteer run this organization" } \\
\text { "We are the ones affected" } \\
\text { "We are a poor organization" }\end{array}$ & $\begin{array}{c}\text { "There is no work like } \\
\text { professional work" }\end{array}$ \\
$\begin{array}{l}\text { Expectations:Volunteer logic } \\
\text { implies unrealistic } \\
\text { expectations of paid staff } \\
\text { output }\end{array}$ & & \\
$\begin{array}{l}\text { Motivation:Trade-off between } \\
\text { managerialism and volunteer } \\
\text { motivation }\end{array}$ & $\begin{array}{l}\text { "Our association relies on } \\
\text { flexibility and personal networks" }\end{array}$ & $\begin{array}{l}\text { "Our organization } \\
\text { relies on standardized } \\
\text { procedures" }\end{array}$ \\
\hline
\end{tabular}

\section{Intraorganizational Conflicts}

In this section, we show how the two different understandings about the organization's identity result in conflict and how intraorganizational tensions can erupt. According to Glynn (2000), tension and conflict emerge when one identity element is emphasized over another. It is through their particular lens (volunteer or managerial) that the organizational actors, by virtue of their organizational position, craft their particular definition of the key attributes of their organization (Glynn, 2000).

All of the workers of the associations (paid or volunteer) emphasized their efforts toward accomplishing the mission of their association. There was no disagreement about the content of the mission itself but about how to reach those goals. Misunderstandings and conflicts emerged from the differing understandings about organizational identity (volunteer identity vs. managerial identity) and from the emphasizing of elements of one identity over the other. In the following, we will describe three essential conflict areas that were present in each of the associations we studied (Table 2).

Authority: Each identity claims authority to lead the organization. Our data showed the different perceptions of volunteers and paid staff working in the same association concerning who should actually lead and if the volunteer or managerial logic should prevail. The volunteers' claim to be the legitimate leaders of the organization is based on three reasons. First, as described in the identity dimensions "We are a volunteer organization" and "Volunteers run our organization," volunteers felt that they should run the organization because as members the organization belonged to them. Second, being personally affected by the disease, they believed that they knew best what to do. This is depicted in the identity dimension, "We are the ones affected." Third, volunteers noticed the high turnover among professionals: 
I have heard people say that they are fed up with the high turnover of the central office staff; they leave every 2 years. They see professional staff come in, do a job for maybe 2 years, and then they move out again. And, of course, if you have the disease, you have it for the rest of your life.

With these three arguments, volunteers emphasized their authority to lead the association. Paid staff members, by contrast, believed that the mission would be accomplished best by a more managerial approach and less volunteer involvement in decision making, as described in the identity dimension, "There is no work like professional work."

Studying the minutes of board meetings from 1990 to 2006 and our interview data, we could track down how this conflict influenced many discussions of board members and the managing director, sometimes in a very explicit but often in a subliminal way. Particularly, the conflict became manifest in tensions between volunteer board members and the paid management team. The following interview quote shows this struggle over authority very explicitly:

This, um, has been an open debate. Our board members want to have a say in many things. Some of the board members have criticized [the managing director] for wanting to do too many things by himself. ... They want the volunteers to be heart.

We observed this fundamental conflict over authority also frequently between the central office (mainly workplace of paid staff) and the local branches (workplace of volunteers):

Historically, there has been an issue of people seeing it as divided. We had so many troubles and fights between our branches in the country and the central office. ... There is a perception of the branches that the central office maybe doesn't acknowledge the good work that we do out here . . . we simply don't have a voice there.

Expectations: Volunteer logic implies unrealistic expectations of paid staff output. From the identity dimension "We are a poor organization," implicit (and sometimes explicit) expectations of volunteers with regard to paid staff emerged. From the volunteer perspective, work is free of charge and resources are scarce. They believed that the organization should do everything possible to save money, whereas the managerial discourse emphasizes the importance of investments to raise more funds ("Money, money, money"). According to the volunteer logic, paid staff must produce an enormous output to justify their salaries. A volunteer board member indicated what they expected from the first managing director they were going to hire:

We have gotten a grant and we have the money to pay someone for 3 years. And during these years, we hope he or she will actually provide us with millions! There is a lot to be done. ... This person will turn everything upside down, and in the end we will have a stronger organization. 
Similarly, one paid employee complained about the unrealistic expectations volunteers put on him when he was hired a few years ago: "It was as if they hired a top soccer player and tell him then, please serve as a coach and masseur as well. That doesn't work!" His reaction was to ask for a formalized job description.

Motivation:Trade-off between managerialism and volunteer motivation. Champions of the managerial identity believed that the association's work should be predictable and structured, as we have shown in the dimension "Our organization relies on standardized procedures." This emphasis on managerial values made volunteers worry about the organization's soul: "I have to say, I hope, I really hope, that the soul of this association will not be lost." Similarly, a founding member expressed her concerns: "You have to be very careful; the heart has to stay where it is. The heart has to remain warm." Furthermore, the flexible, helpful, and personal working style ("Our association relies on flexibility and personal networks") was, in their eyes, the best way to actually achieve the mission: to support all people with the disease, their families, friends, and caregivers. On the other side, a managing director observed the conflict from her perspective and stated, "There was so much resistance against anything that looked like paperwork." Our findings suggest that overformalization ("Our organization relies on standardized procedures") can be off-putting to volunteers. Volunteering seems to be about creativity, freedom of action, and choice ("Our association relies on flexibility and personal networks"), values that sit uneasily with formal management tools, such as job descriptions and disciplinary and grievance procedures. Conflicts emerged with the introduction of structured management instruments, such as strategic planning, marketing, or benchmarking, because formalization had significant negative impacts on volunteer motivation: "In the end it became really difficult. All these regulations, standing orders, and concepts, it is just so much paper. I got tired of this." Tensions erupted over the introduction of written regulations. One volunteer said angrily, "You have to understand, we all work voluntarily and without pay and then they come and patronize us, foisting their regulations on us!" The narration of the managing director of one northern European association might serve as another example of the trade-off between managerialism and volunteer motivation. $\mathrm{He}$ reported how they had introduced management instruments over the preceding 4 years and how this enabled them to raise a considerably larger amount of funds. As a consequence, the association raised the number of employees from one to six and expanded the array of services and products considerably. Offering all these new services to their members, one would expect that also the number of members would have increased significantly during those 4 years. On the contrary, "We have not been able to attract new members; instead the number of members has decreased. We don't know why," the manager explained. He did not recognize that by introducing management instruments and implementing standardized processes they had lost the volunteers' commitment.

\section{Conclusion}

This qualitative field study examined the conflict between two key identity elements of voluntary associations: volunteering and managerialism. Our narrative interviews 
shed light on the duality of identity of the examined associations, which was ideographic in nature. Contradictory identity dimensions coexisted and were claimed by different groups within the organizations. Describing the volunteer identity of the patient organizations, we identified five key dimensions: "We are a volunteer organization," "We are a poor organization," "Volunteers run our organization," "Our association relies on flexibility and personal networks," and "We are the ones affected." By contrast, "There is no work like professional work," "Money, money, money," and "Our organization relies on standardized procedures" were the dimensions of the managerial identity we observed. It became obvious that ideologies of volunteers and paid staff were at odds over the allocation of the associations' resources. The three conflict areas, authority, expectations, and motivation, we described are examples of how tensions between volunteers and paid staff can erupt. We showed how many of the conflicts between these two groups are deeply rooted in different perceptions about the organization's identity.

The conflict areas "each identity claims authority to lead the organization" and "volunteer logic implies unrealistic expectations of paid staff output" seem to be underresearched to date. An exception is Hoggett and Bishop (1986), who suggest that "members perceive a fundamental difference between 'by some of us for all of us' and "by them for us"" (p. 41). Also, with regard to the conflict about who has the authority to lead the organization, Milofsky (1988) emphasizes how associations might find it difficult to unseat or control people who become entrenched and who choose to treat their volunteer jobs as a personal domain.

Our study examined the effects of the introduction of bureaucratic procedures and management instruments and of a higher involvement of paid professionals in the nonprofit sector and shows how this new managerialism (Hwang \& Powell, 2009) leads to a decline in volunteer motivation. Indeed, the conflict area "trade-off between managerialism and volunteer motivation" has received the greatest attention in the existing literature. The discussion goes back to Max Weber (1922/1976), who identified the dangers of routinization that ideologically minded organizations face when they seek to introduce enduring structures and procedures. He saw, however, no way out: "You only have the choice between 'bureaucratization' and 'dilettantism" (Weber, 1922/1976, p. 128). Moreover, without deliberate efforts to the contrary, associational structures tend to become more rigid and member relations more formal as groups reorganize for long-term stability (Rothschild-Whitt, 1979). Our findings confirm Milofsky's (1988) suggestion that the institution of bureaucracy threatens participatory impulses. Knoke and Wood (1981) examined psychological and behavioral commitment in 32 local chapters of associations. They found that the more widespread a person's participation in collective decision making and the greater his or her integration into the communication structure, the higher the member's commitment to the association (positive affect, loyalty, and efforts to realize group goals) and the lower the detachment (personal remoteness and feelings of inability to influence collective actions and policies). Smith (1996) argues that organizations need not abandon management altogether but should choose the style best suited to the culture and ethos of the association. Similarly, Ilsley commented, 
Managing professionalism in a way that allows organizations to reap its benefits without having the spontaneity and life checked out of them by its rigidifying force is likely to be one of the greatest challenges that volunteer managers will face in the coming years. (Ilsley, 1990, p. 89)

However, how can these two conflicting identity dimensions be reconciled for the good of the organization? Pratt and Foreman (2000) suggest that multiple identities can be managed in various ways, sometimes to the advantage of an organization. Overall, researchers have identified various organizational strategies for coping with dual identities, including eliminating some identities, exploiting their advantages through compartmentalization or integration, tolerating and enduring the problems of multiple identities, finding a higher level (meta)identity that successfully integrates existing identities, creating an entirely new identity, and downplaying the problems and allowing one or more identities to slowly decay (Pratt \& Foreman, 2000; Whetten \& Godfrey, 1998). According to Stone (1996), organizations must sometimes create multiple identities to be able to deal with conflicting environmental pressures. Albert and Whetten (1985) assert that members of ideographic organizations are better prepared to monitor diverse environmental conditions and to formulate appropriate recommendations for adaptive organizational modifications. However, multiple identities can also be paralyzing and unstable (Whetten \& Godfrey, 1998).

This analysis is limited in three ways. First, any dimension of the above-described dimensions of volunteer identity and managerial identity might depend on the specific circumstances the examined patient organizations faced. To improve the transferability (Lincoln \& Guba, 1985) of our findings, we studied associations working in different national contexts. Second, we did not differentiate between volunteers serving on the board of directors or working at the basic, grassroots level of the association. Even though we interviewed volunteers from each level of the individual organizations, board members may have been overrepresented in our sample. We did not find any significant differences in the perceptions of volunteers about their organization's identity at the different levels of the associations. Nevertheless, future research may be necessary to examine more in detail the nuances of how volunteers at all levels of the organization construct their perceptions of its identity. In addition, future research could explore the effects of dual identities in voluntary associations on their image and on relations to external stakeholders, such as clients, donors, or government officials. Third, even though we analyzed intraorganizational conflicts, our analysis is limited because we did not focus specifically on how the two identity dimensions interrelate. Further research might analyze how the two groups construct their image of each other and whether there is a dynamic quality to the relationship between dual identities and conflict that works to strengthen each (and probably weaken the association).

The results of our study have important implications for research on volunteering and voluntary associations. As we have shown, most studies on volunteering adopt a microview (the single volunteer as unit of analysis) or a macroview (importance of volunteering for society at large). An exception is the study by Kelley et al. (2005), who analyzed the importance of volunteering for organizational transition. In our study, we 
extended their view by taking up a purely organizational perspective and studied volunteering as an organizational phenomenon. In the future, research could beneficially explore further the challenges of volunteering for organization and management. Furthermore, our findings contribute to existing research on dual organizational identity (Glynn, 2000; Golden-Biddle \& Rao, 1997) by carefully describing how differing beliefs about an organization's identity are constructed and result in intraorganizational conflict and how multiple versions of an organization's identity are interpreted as symptomatic of a hegemonic struggle in which competing individuals and groups attempt to render dominant their version of what the organization should stand for (Brown, 2007).

Finally, our research has implications for leadership and management of dual-identity associations. It was stated that "effective leaders of dual identity organizations should personify and support both identities" (Albert \& Whetten, 1985, p. 288). In the case of voluntary associations, this means that the managing director and the president of the board should be perceived as champions of the volunteer as well as of the managerial values of the organization. Thus, they should fully embrace the organizations' key identity and claim the key ideologies as their own (Glynn, 2000). A quasi-volunteer managing director or a quasi-managerial president of the board might overemphasize one identity dimension over the other and consequently intensify the conflict even more. Organizational leaders need to carefully attend to the narratives of the association's identity. Both paid staff and volunteers alike have to carefully integrate the different understandings of what the organization is really about into a broader picture, a metaidentity, that everyone can identify with.

Finally, leaders of voluntary associations have to understand their responsibility toward the broader society. Volunteers are not only a cheap source of labor but integrating people with different backgrounds is also a major task for all associations independent of their mission. De Tocqueville (1835) saw citizens' participation in associations as a foundation of democracy, and he identified participation and inclusion as central functions of associations against the so-called tyranny of the majority. Similarly, the French sociologist Emil Durkheim (1933) argued that voluntary associations play the role of social glue in societies with high division of labor, professional specialization, economic competition, and social stratification.

\section{Declaration of Conflicting Interests}

The authors declared no potential conflicts of interests with respect to the authorship and/or publication of this article.

\section{Financial Disclosure/Funding}

The authors received no financial support for the research and/or authorship of this article.

\section{References}

Albert, S., \& Whetten, D. A. (1985). Organizational identity (Vol. 7). Greenwich, CT: JAI Press. Alexander, J. A., \& Weiner, J. W. (1998). The adoption of the corporate governance model by nonprofit organizations. Nonprofit Management and Leadership, 8, 223-470. 
Anheier, H. K. (2005). Nonprofit organizations. Theory, management, policy. New York: Routledge.

Anheier, H. K., \& Salamon, L. M. (1999). Volunteering in cross-national perspective. Law \& Contemporary Problems, 62(4), 43-65.

Badelt, C. (2002). Ehrenamtliche Arbeit im Nonprofit Sektor [Volunteering in the nonprofit sector]. In C. Badelt (Ed.), Handbuch der Nonprofit Organisation. Strukturen und Management (pp. 433-462). Stuttgart, Germany: Schäffer-Poeschel.

Beyes, T., \& Jäger, U. (2005). Erforschung multi-diskursiver Organisationen [Research in multidiscursive organizations]. Die Betriebswirtschaft, 6, 627-651.

Brainard, L. A., \& Siplon, P. D. (2004). Toward nonprofit organization reform in the voluntary spirit: Lessons from the Internet. Nonprofit and Voluntary Sector Quarterly, 33, 435-457.

Brown, A. D. (2007). Organizational identity. In S. L. Clegg \& J. R. Bailey (Eds.), International encyclopedia of organization studies. Thousand Oaks, CA: Sage.

Brown, D. L., \& Moore, M. H. (2001). Accountability, strategy, and international nongovernmental organizations. Nonprofit and Voluntary Sector Quarterly, 30, 569-587.

Brudney, J. L., \& Gazley, B. (2002). Testing the conventional wisdom regarding volunteer programs: A longitudinal analysis of the service corps of retired executives and the U.S. Small Business Administration. Nonprofit and Voluntary Sector Quarterly, 31, 525-548.

Clary, E. G., Snyder, M., \& Stukas, A. A. (1996). Volunteers' motivations: Findings from a national survey. Nonprofit and Voluntary Sector Quarterly, 25, 485-505.

Corley, K. G., \& Gioia, D. A. (2004). Identity ambiguity and change in the wake of a corporate spin-off. Administrative Science Quarterly, 49, 173-208.

Czarniawska, B. (1997). Narrating the organization, dramas of institutional identity. Chicago: University of Chicago Press.

Dart, R. (2004). Being "business-like" in a nonprofit organization: A grounded and inductive typology. Nonprofit and Voluntary Sector Quarterly, 33, 290-310.

de Tocqueville, A. (1835). Democracy in America. New York: Literary Classics of the United States.

Drucker, P. F. (1990). Managing the nonprofit organization. New York: HarperCollins.

Durkheim, E. (1933). The division of labour in society. New York: Free Press.

Dutton, J. E., \& Dukerich, J. M. (1991). Keeping an eye on the mirror: Image and identity in organizational adaptation. Academy of Management Journal, 34, 517-554.

Flanagan, J. C. (1954). The critical incident technique. Psychological Bulleting, 51, 327-358.

Froschauer, U., \& Lueger, M. (2003). Das qualitative Interview [The qualitative interview]. Stuttgart, Germany: Facultas.

Gaskin, K., \& Smith, J. D. (1997). A new civil Europe? A study of the extent and role of volunteering. London: National Volunteering Centre.

Geertz, C. (1983). Local knowledge. New York: Basic Books.

Gioia, D. A., Schultz, M., \& Corley, K. G. (2000). Organizational identity, image, and adaptive instability. Academy of Management Review, 25(1), 63-81.

Gioia, D. A., \& Thomas, J. (1996). Identity, image and issue interpretation: Sensemaking during strategic change in academia. Administrative Science Quarterly, 41, 370-403.

Glynn, M. A. (2000). When cymbals become symbols: Conflict over organizational identity within a symphony orchestra. Organization Science, 11, 285. 
Golden-Biddle, K., \& Rao, H. (1997). Breaches in the board room: Organizational identity and conflict of commitment in a non-profit organization. Organization Science, 8, 593-611.

Harris, M. (1998). Doing it their way: Organizational challenges for voluntary associations. Nonprofit and Voluntary Sector Quarterly, 27, 144-158.

Hedley, R., \& Smith, J. D. (1994). Volunteers and the contract culture. London: Volunteer Center U.K.

Hermanns, H. (1991). Narratives interview. In U. Flick, v. E. Kardorff, H. Keupp, v. L. Rosenstiel \& S. Wolff (Eds.), Handbuch Qualitative Sozialforschung. [Handbook qualitative social science.]. München, Germany: Psychologie Verlags Union.

Hoggett, P., \& Bishop, J. (1986). Organizing around enthusiasms. London: Comedia.

Howlett, S., \& Rochester, C. (2007). Organising the work of volunteers: Towards a non-managerial paradigm. Paper presented at the 6th Workshop on the Challenges of Managing the Third Sector, Venice, Italy.

Humphreys, M., \& Brown, A. D. (2002). Narratives of organizational identity and identification: A case study of hegemony and resistance. Organization Studies, 23, 421.

Hwang, H., \& Powell, W. W. (2009). The rationalization of charity: The influences of professionalism in the nonprofit sector. Administrative Science Quarterly, 54, 268-298.

Ilsley, P. (1990). Enhancing the volunteer experience. San Francisco: Jossey-Bass.

Jäger, U., \& Beyes, T. (2010). Strategizing in NPOS: A case study on the practice of organizational change between social mission and economic rationale. Voluntas: International Journal of Voluntary and Nonprofit Organizations, 21, 82-100.

Jäger, U., Kreutzer, K., \& Beyes, T. (2009). Balancing acts: NPO-leadership and volunteering. Financial Accountability \& Management, 25(1), 79-97.

Jehn, K. A., Northcraft, M. A., \& Neale, M. A. (1999). Why do differences make a difference: A field study of diversity, conflict, and performance in workgroups. Administrative Science Quarterly, 44, 741-763.

Kelley, M. S., Lune, H., \& Murphy, S. (2005). Doing syringe exchange: Organizational transformation and volunteer commitment. Nonprofit and Voluntary Sector Quarterly, 34, 362-386.

Kieser, A. (1994). Why organization theory needs historical analyses - and how this should be performed. Organization Science, 5, 608-620.

Knoke, D., \& Wood, J. R. (1981). Organized for action: Commitment in voluntary associations. New Brunswick, NJ: Rutgers University Press.

Kreutzer, K. (2009). Nonprofit governance during organizational transition in voluntary associations. Nonprofit Management \& Leadership, 20(1), 117-133.

Kumar, N., Stern, L. W., \& Anderson, J. C. (1993). Conducting interorganizational research using key informants. Academy of Management Journal, 36, 1633-1651.

Lincoln, Y. S., \& Guba, E. G. (1985). Naturalistic inquiry. Beverly Hills, CA: Sage.

Macduff, N. (1995). Volunteer and staff relations. In T. D. Connors (Ed.), The volunteer management handbook (pp. 206-221). New York: John Wiley.

Maier, F., \& Meyer, M. (2009). "Business-like” form without "business-like” substance? The thin line between nonprofit managerialism and economization [Working paper]. Vienna: Vienna University of Economics and Business, Department of Nonprofit Management.

Mason, J. (2002). Qualitative interviewing: Asking, listening and interpreting. In T. May (Ed.), Qualitative research in action (pp. 225-241). London: Sage. 
McCurley, S., \& Lynch, R. (1997). Essential volunteer management. London: Directory of Social Change.

Milofsky, C. (1988). Community organizations: Studies in resource mobilization and exchange. Oxford, UK: Oxford University Press.

Moore, M. H. (2000). Managing for value: Organizational strategy in for-profit, nonprofit and governmental organizations. Nonprofit and Voluntary Sector Quarterly, 29, 183-204.

Morgan, D. L. (1988). Focus groups as qualitative research. Newbury Park, CA: Sage.

Mouly, V. S., \& Sankaran, J. K. (1997). On the study of settings marked by severe superiorsubordinate conflict. Organization Studies, 18, 175-192.

Olson, M. (1965). The logic of collective action. Public goods and theory of groups. Cambridge, MA: Harvard University Press.

Omoto, A. M., \& Snyder, M. (1995). Sustained helping without obligation: Motivation, longevity of service, and perceived attitude change among aids volunteers. Journal of Personality and Social Psychology, 68, 671-686.

Paulwitz, I. (1988). Freiwillige in sozialen diensten: Volunteers und professionelle im wohlfahrtssektor der USA [Volunteers in social services: Volunteers and professionals in the welfare sector of United States]. Weinheim, Germany: Juventa.

Pearce, J. (1982). Leading and following volunteers. Implications for a changing society. Journal of Applied Behavioral Science, 18, 385-394.

Pearce, J. (1993). Volunteers. The organizational behavior of unpaid workers. London: Routledge. Pollitt, C. (1993). Managerialism and the public services (2nd ed.). Oxford, UK: Blackwell.

Pratt, M. G., \& Foreman, P. O. (2000). Classifying managerial responses to multiple organizational identities. Academy of Management Review, 25(1), 18-42.

Regnet, E. (2002). Alles Paletti? Volunteers und Konfliktmanagement. [Volunteers and conflict management.] In D. Rosenkranz \& A. Weber (Eds.), Freiwilligenarbeit. Eine Einführung in das Management von Ehrenamtlichen in der sozialen Arbeit [Volunteer work. An introduction to the management of volunteers in social work] (pp. 103-117). Weinheim, Germany: Juventa.

Rosenbladt, B. V. (2000). Freiwilliges Engagement in Deutschland. Ergebnisse Der Repräsentativerhebung 1999 Zu Ehrenamt, Freiwilligenarbeit Und Bürgerschaftlichem Engagement, Gesamtbericht [Volunteering in Germany. Results of the sample survey in 1999 to volunteer, volunteering, and civic engagement, general report]. Stuttgart, Germany: Kohlhammer.

Rothschild-Whitt, J. (1979). The collectivist organization: An alternative to rational-bureaucratic models. American Sociological Review, 44, 509-527.

Salamon, L. M. (1993). The marketization of welfare: Changing nonprofit and for-profit roles in the American welfare state. Social Service Review, 67(1), 16-39.

Schütze, F. (1977, August). Die Technik des narrativen Interviews. [The technique of narrative interviewing.]. Unpublished manuscript, University of Bielefeld, Department of Sociology, Bielefeld, Germany.

Scott, S. G., \& Lane, V. R. (2000). A stakeholder approach to organizational identity. Academy of Management Review, 25(1), 43-62.

Simsa, R. (2001). Gesellschaftliche Funktionen Und Einflußformen Von Nonprofit-Organisationen. Eine Systemtheoretische Analyse [Social functions and influence of forms of nonprofit organizations. A system theoretical analysis]. Frankfurt, Germany: Peter Lang Verlag. 
Smith, D. H. (1997). The rest of the nonprofit sector: Grassroot associations as the dark matter ignored in prevailing flat earth maps of the sector. Nonprofit and Voluntary Sector Quarterly, 26, 114-131.

Smith, J. D. (1996). Should volunteers be managed? In D. Billis \& M. Harris (Eds.), Voluntary associations (pp. 187-199). London: McMillan.

Stone, M. M. (1996). Competing contexts: The evolution of a nonprofit organization's governance system in multiple environments. Administration \& Society, 28, 61-89.

Strauss, A., \& Corbin, J. (1998). Basics of qualitative research. Techniques and procedures for developing grounded theory. Thousands Oaks, CA: Sage.

Tschirhart, M. (2006). Nonprofit membership associations. In W. W. Powell \& R. Steinberg (Eds.), The nonprofit sector. A research handbook (pp. 523-542). New Haven, CT: Yale University Press.

Van de Ven, A. H., \& Poole, M. S. (1990). Methods for studying innovation development in the Minnesota Innovation Research Program. Organization Science, 1, 313-335.

Weber, M. (1976). Wirtschaft und Gesellschaft [Economy and society] (Vol. 2, Auflage). Tübingen, Germany: JCB Mohr. (Original work published 1922)

Weick, K. E. (1995). Sensemaking in organizations. London: Sage.

Weisbrod, B. A. (1998). To profit or not to profit: The commercial transformation of the nonprofit sector. New York: Cambridge University Press.

Whetten, D. A., \& Godfrey, P. C. (1998). Identity in organizations. London: Sage.

Wood, M. M. (1996). Nonprofit boards and leadership. Cases on governance, change and board-staff dynamics. San Francisco: Jossey-Bass.

Young, D. R. (2001). Organizational identity and the structure of nonprofit umbrella associations. Nonprofit Management and Leadership, 11, 289-304.

\section{Bios}

Karin Kreutzer is a senior research fellow of strategic and nonprofit management at the Institute of Management at the University St. Gallen in Switzerland. Her current research interests include voluntary associations, organizational identity, and nonprofit strategy.

Urs Jäger is a professor of nonprofit management at the University St. Gallen in Switzerland. $\mathrm{He}$ is the managing director of the Center for Leadership and Values in Society. His research interests are nonprofit strategy, accountability, and governance as well as social business and social enterprise. 